\title{
A GARIMPAGEM DE OURO NA OCUPAÇÃO, POVOAMENTO E DEFINIÇÃO DOS LIMITES ENTRE BRASIL E GUIANA FRANCESA
}

\author{
The Artisanal Gold Mining in The Occupation, Settlement and \\ Establishment of The Borders between Brazil and French Guiana
}

David Souza Góes*

\begin{abstract}
RESUMO: Considerando que as fronteiras definidas pelos Estados condicionam o movimento das populações, as quais respondem de diferentes maneiras aos efeitos desses limites, este artigo objetiva analisar a mobilidade dos agentes envolvidos em atividades vinculadas à garimpagem de ouro na ocupação, povoamento e definição do limite franco-brasileiro, precipuamente daqueles agentes que tiveram as comunidades localizadas no rio Oiapoque como apoio logístico. Baseandose no método materialismo histórico e dialético, observou-se que esses agentes, com suas atividades e suas práticas espaciais, foram e são centrais na ocupação, povoamento e urbanização na fronteira franco-brasileira, em especial na cidade de Oiapoque, que ainda hoje apresenta dinâmicas socioeconômicas decorrentes da garimpagem informal aurífera na área de contato entre Brasil e Guiana Francesa. Essa constatação ratifica a necessidade de se reconhecer a diversidade que configura os processos de mobilidade humana e de urbanização na região que, em muito, decorrem de processos extra-locais, em especial nas cidades fronteiriças.

Palavras-chave: Garimpagem do ouro. Urbanização. Fronteira franco-brasileira. Cidade de Oiapoque. Amazônia.
\end{abstract}

ABSTRACT: Considering that the borders defined by the Nation States condition the movement of the populations, which, in turn, respond in different ways to the effects of those limits, this article aims to analyze the mobility of the agents involved in artisanal gold mining-related activities in the occupation, settlement and establishment of the Franco-Brazilian border, with special emphasis on those agents whose logistical supports were the communities located along the Oiapoque River. Based on the historical and dialectical materialist method, it was observed that these agents, with their activities and spatial practices, were and still remain central in the occupation, settlement and urbanization in the Franco-Brazilian border, especially in the town of Oiapoque, which still presents socioeconomic dynamics related to the informal artisanal gold mining in the border areas between Brazil and French Guiana. This finding confirms the need to recognize the diversity that shapes the processes of human mobility and urbanization in the region, largely resulting from extra-local processes, especially in border towns.

Keywords: Artisanal gold mining. Urbanization. Franco-Brazilian border. Town of Oiapoque. Amazon.

\footnotetext{
* Doutorado em Desenvolvimento Socioambiental. Pós-graduação em Desenvolvimento Sustentável do Trópico Úmido-NAEA, PDTU/NAEA/UFPA. E-mail: davigos@bol.com.br
} 


\section{Introdução}

A Amazônia, ao longo da história, vem sendo vista e adjetivada de forma homogênea (paraíso perdido, el dorado, espaço rico e vazio demograficamente), como se fosse uma área sem ocupação e sem divisões. Porém, na realidade, só a Amazônia Sul-Americana, que corresponde a 1/20 da superfície terrestre e a $2 / 5$ da América do Sul, é compartilhada por nove países e um departamento ultramarino da França, a Guiana Francesa (BECKER, 1997); fato esse que, por si só, é capaz de revelar um quadro bastante diverso e que em muito representa a complexidade cultural, econômica, física, política e territorial que configura o espaço amazônico, o qual, por seu turno, apresenta algumas particularidades no que diz respeito às suas fronteiras.

Contudo, convém destacar, inicialmente, alguns sentidos atribuídos à ideia de fronteira. Isso porque, se no pensamento geopolítico ela figura com o significado de divisor entre soberanias territoriais (SPRANDEL, 2005), em uma perspectiva antropológica, que leva em consideração a articulação de identidades nas condições existenciais dos habitantes fronteiriços, a fronteira não divide, mas conjuga nacionalidades e etnicidade, como lembra Cardoso de Oliveira (1997). Ao ponderar sobre a pertinência de categorias do pensamento geográfico relacionadas à noção de fronteira, Trindade Júnior (2010) afirma que a fronteira é um elemento relacional e que possui sentidos sócio-históricos, ou seja, a fronteira resulta de relações históricas que são construídas entre diferentes sociedades, tanto do ponto de vista cultural e econômico, quanto político.

Dessa maneira, na faixa de fronteira brasileira encontram-se lugares de convergência de redes $^{1}$ de relações, muitas das quais transcendem os limites políticos que fazem a delimitação das soberanias nacionais. Refletindo sobre as interações sociais entre brasileiros e franceses na fronteira franco-brasileira ${ }^{2}$, Martins (2014) afirma que a busca pelo ouro em garimpos ilegais na Guiana Francesa é o motivo que explica tais transcendências. Considerando-se a fronteira do Brasil com a Venezuela, ou com a Guiana, também há estudos empíricos que confirmam as práticas de atravessamento, impulsionadas pela garimpagem ${ }^{3}$ de ouro. Esta atividade é vista por muitos brasileiros como estratégia de enriquecimento rápido ou fonte de renda para melhor condição de vida (BECKER, 2004; CORBIN, 2012).

No município de Oiapoque (AP), mais precisamente às margens do rio Oiapoque ${ }^{4}$, encontra-se a cidade sede do município - cuja denominação é homônima ao rio - e a pequena comunidade de Vila Brasil, as quais fazem limite respectivamente com duas comunas ${ }^{5}$ francesas, SaintGeorges e Camopi. A cidade e a vila supracitadas apresentam, na atualidade, continuidades em suas dinâmicas sociais dos processos históricos de ocupação, caracterizados em grande parte pela mobilidade de pessoas e práticas comerciais articuladas pela descoberta de jazidas auríferas em ambos os lados do limite internacional entre o Brasil e a Guiana Francesa (ALICINO, 1971; MORAES,

\footnotetext{
1 Nos estudos sobre fronteira, a noção de rede indica: a circulação, a contiguidade e descontinuidade, elas têm o sentido de sistema de fluxos (movimentos) e fixos (nós) que definem uma dada organização espacial; elas são ao mesmo tempo, concentradoras e dispersoras, condutoras de forças centrípetas e de forças centrífugas (SANTOS, 2006; TRINDADE JÚNIOR, 2010).

2 A maior fronteira franco-brasileira com 730,4 km de extensão, dos quais 427,2 km são por rios e 303,2 km por divisores de águas km, é a maior fronteira da França (COSTA; CUNHA, 2017).

3 Como aponta Lins (1992), uma atividade de aproveitamento imediato de substâncias minerais garimpáveis.

${ }^{4}$ A palavra Oiapoque origina-se da língua Tupi (oyap oca), que significa "Casa dos Oiampis" ou "Casa dos Guerreiros ou parentes" (ROMANI, 2010).

5 Silva (2014) informa que "comuna" é a denominação francesa para unidades territoriais que, se comparadas ao Brasil, podem ser entendidas como o município.
} 
1964; BECKER, 2004; ROMANI, 2010; SILVA, 2014).

Com base nesse contexto e na importância atribuída por diversos agentes sociais à atividade garimpeira nessa região (GÓES, 2014, 2019), o presente artigo indica algumas problemáticas em escala local pertinentes à elaboração de políticas públicas com concepções alinhadas à sustentabilidade socioeconômica e ambiental dessa realidade. Assim, destaca-se a seguinte questão-problema norteadora de nossas argumentações: os agentes diretamente relacionados à atividade garimpeira ${ }^{6}$ entre Brasil e Guiana Francesa foram centrais na ocupação, na definição dos limites franco-brasileiros e na gênese da cidade de Oiapoque?

Nesse sentido, levando-se em consideração a teoria da produção do espaço (LEFÈBVRE, 2000) e as informações que foram coletadas em documentos municipais, observações não-participantes e relatos dos interlocutores abordados, objetiva-se destacar o desenvolvimento histórico dos conjuntos espaciais na fronteira franco-brasileira, tendo como perspectiva analítica o papel que os componentes socioeconômicos da garimpagem de ouro desempenharam nos processos ocupação e povoamento dessa fronteira.

Além do mais, a execução de operações de vigilância ao trânsito de brasileiros no rio Oiapoque implica, de acordo com os entrevistados, em uma redução significativa na circulação monetária, bem como uma diminuição no consumo de mercadorias e serviços; operações essas cujo principal intuito é impedir que garimpeiros e insumos cheguem aos garimpos clandestinos localizados em solo guianense ${ }^{7}$. Por esta razão, almeja-se, outrossim, analisar a relevância da garimpagem de ouro para as vivências dos moradores da cidade de Oiapoque, na fronteira franco-brasileira, haja vista a importância da atividade em questão nesse espaço urbano.

Em vista disso, além desta introdução e das considerações finais, o texto encontra-se estruturado em três partes: na primeira, busca-se discutir o papel da garimpagem do ouro no contexto dos processos de ocupação e definição da fronteira franco-brasileira, enquanto na segunda e na terceira, reflete-se, respectivamente, acerca dos movimentos de ocupação e povoamento empreendidos pelo governo brasileiro nesse espaço e da continuidade das atividades garimpeiras na motivação da presença do estado brasileiro na porção territorial em tela.

\section{A garimpagem de ouro na ocupação e definição dos limites entre Brasil e Guiana Francesa}

$\mathrm{Na}$ literatura produzida sobre a região do Oiapoque está consolidada a tese de que a mobilidade de pessoas, o extrativismo do ouro e o comércio de mercadorias de subsistência são os fenômenos encontrados em sua formação socioeconômica. Nessa direção, apontam-se as reflexões de Alicino (1971), Soares (1995), Rodrigues (2008), Romani (2010, 2011, 2013) e Martins (2014), que argumentam sobre como a extração do ouro e sua consequência imediata à "passagem", aqui definida como atravessamento da fronteira, tornaram-se atributos do viver na cidade de Oiapoque em sua multidimensionalidade, seja na cidade, na fronteira ou mesmo no rio.

A fronteira territorial existente entre Brasil e Guiana Francesa passou por uma intensa

\footnotetext{
${ }^{6}$ A garimpagem de ouro na Amazônia é realizada pela mineração artesanal informal, mineração por cooperativas e mineração formal-empresarial (THEIJE; LUNING, 2016; COELHO; WANDERLEY; COSTA, 2017).

7 A partir do ano de 2008, as autoridades francesas reforçaram a presença militar na fronteira a fim de combater a extração ilegal do ouro e a clandestinidade; e pelo lado brasileiro, o governo organizou grandes ações, como as operações Anaconda, Harpie e Ágata, que integram o Plano Estratégico de Fronteira (SUPERTI; SILVA, 2015).
} 
história de deslocamentos fortemente atrelada aos desdobramentos provenientes dos acontecimentos desencadeados pelos procedimentos de expansão territorial e a busca de ouro (SOARES, 1995). Entre os países que foram catalisadores desse processo, encontravam-se Portugal e França, tendo em perspectiva os inúmeros conflitos que fomentaram em ambas as nações o litígio pela posse da área que se estendia do rio Oiapoque ao Araguari (ROMANI, 2010).

As ações por parte dos países que pleiteavam marcar poder e presença na área questionada ocorriam em dois movimentos: os luso-brasileiros partiam de Belém, Gurupá, Desterro ou Paru, protegidos pelo destacamento do Araguari, Colônia Militar D. Pedro II, e se deslocavam ao longo do litoral com pequenos números de embarcações, coletando matéria- prima para suas operações mercantis. Enquanto isso, o segundo movimento se dava, de forma silenciosa e cautelosa, pela penetração francesa nas terras em litígio, evitando demarcar sua posição de maneira ostensiva (REIS, 1949; ALICINO, 1971; ROMANI, 2010).

Assim como os mercadores franceses operavam por meio do escambo com os indígenas da região, também realizavam a escravização desses. Dessa maneira, esse movimento foi tomando vulto à medida que Marquês de Férrolles, em Caiena, concedia autorização para os mercadores franceses irem além do rio Vicente Pinzón - rio Oiapoque -, atingindo as terras de soberania portuguesa (REIS 1949; ALICINO, 1971).

Destaca-se que a parte norte das terras que compõem o atual estado do Amapá foi objeto de um litígio entre Portugal e França, até 1822, e, depois, entre França e Brasil. Tratava-se de definir a qual País caberia a soberania territorial sobre a área. Esse último litígio, por sua vez, inicia-se em fins do século XVII, estando, nessa ocasião, relacionado ao comércio praticado com os indígenas. Nas negociações para resolver a pendência, as metrópoles, Portugal e França, convencionaram a neutralidade da área no ano de 1700, situação que permaneceu até 1713, quando foi assinado o Tratado de Utrecht, que convencionou o rio Oiapoque, também denominado de Vicente Pizón, como limite entre a Guiana Francesa e a Capitania do Cabo Norte ou Guiana Portuguesa (atual Amapá) (REIS, 1949).

Esse acordo não impediu que a França continuasse a protestar posse sobre as citadas terras. As reclamações francesas eram referentes à localização geográfica do rio Vicente Pizón que, argumentavam os franceses, não era o mesmo rio Oiapoque. Quanto a isso, cumpre lembrar a afirmação da historiadora Acevedo Marin (2004) de que os conflitos no Contestado franco-brasileiro decorriam da localização do curso dos rios.

De qualquer forma, outra neutralização de soberania veio a ocorrer em 1841, após uma série de reuniões na cidade de Paris, entre autoridades brasileiras e autoridades francesas, que buscavam resolver a pendência territorial secular. Desde então, a região passou a ser governada por dois representantes, um francês e um brasileiro, situação esta que perdurou até 1893, quando foi descoberta uma jazida aurífera na área (COELHO; QUEIROZ, 2001).

Em 1893, o ouro encontrado na região do Calçoene provocou uma invasão de garimpeiros na região do Contestado franco-brasileiro, sendo que estes eram, em sua maioria, nativos da Guiana Francesa e das ilhas do Caribe. A descoberta "[...] parece ter feito aumentar os anseios que os franceses de Caiena tinham de expandir as fronteiras da colônia em direção ao rio Amazonas" (COELHO; QUEIROZ, 2001, p. 124), levando-os, em 1895, a uma tentativa de invasão da Vila do Amapá tendo como justificativa libertar franceses que ali estariam presos; episódio esse que desemboca num conflito armado.

Tal acontecimento ficou conhecido nos jornais brasileiros como o "Massacre do Amapá". Dada a dimensão que tomou pela morte de 38 pessoas no embate, e a divulgação na imprensa, 
Brasil e França voltaram a buscar solução para o impasse no território do Contestado franco-brasileiro (COELHO; QUEIROZ, 2001; ROMANI, 2010), tendo como árbitro o governo suíço.

No certame, o brasileiro Barão do Rio Branco, municiado de farta documentação, comprovou que o rio Vicente Pinzón - questionado pelos franceses - na verdade era o rio Oiapoque, e que a maior parte da área questionada era ocupada por brasileiros que mantinham redes comerciais mais ligadas a Belém, no Pará, do que a Caiena, na Guiana Francesa (ALICINO, 1971; GRANGER, 2011).

A competente argumentação de Barão do Rio Branco fez com que, no dia $1^{\circ}$ de dezembro de 1900, na cidade de Berna, na Suíça, a arbitragem da questão sentenciasse a favor do Brasil e a área em questão fosse anexada ao Brasil, sendo, assim, incorporada à soberania brasileira em 25 de fevereiro de 1900 por Decreto Legislativo, com a denominação de território do Aricari. No entanto, a área anexada continuou praticamente abandonada pelas políticas republicanas brasileiras (ALICINO, 1971; ROMANI, 2013).

O descaso pela área anexada nos vinte anos que se seguiram contribuiu para que toda a nova região fronteiriça brasileira permanecesse dominada por negócios de contrabando. Isso porque, como destaca Romani (2013), além dos indígenas que lá viviam, também se podia observar a presença de muitos habitantes que eram garimpeiros remanescentes do ciclo do ouro. Dessa forma, o autor aponta que a exploração econômica da referida área continuava por franceses que contrabandeavam as riquezas para o outro lado do rio.

Em 1907, sete anos após a sentença, ocorreu a primeira ação do governo brasileiro na área anexada. Com intuito de incentivar o povoamento e proteger a fronteira, o governo transferiu do rio Araguari ao rio Oiapoque a Colônia Militar D. Pedro II, “[...], mas o abandono em que foi deixado pelas autoridades estaduais the tirou toda a eficácia na ação fiscalizadora, defensiva e povoadora" (ALICINO, 1971, p. 114).

O descaso deixou poucos registros históricos do processo de ocupação e povoamento da área do contestado na qual se encontra o atual município de Oiapoque. Para superar as limitações dos registros históricos em suas produções bibliográficas sobre o processo de ocupação/povoamento e formação da cidade, antigo povoado Martinica, Alicino (1971) e Romani (2010) em seus estudos empíricos recorreram ao que permaneceu como memória popular na busca de entender o que havia se estabelecido em caráter quase de lenda e o que se constituiu como verdade histórica, ou a história oficialmente determinada.

Romani (2010, 2011), além dos documentos históricos, recorreu a relatos de pessoas reconhecidas na cidade de Oiapoque como portadoras de informações referentes à origem da cidade. Entre elas, a professora Therezinha Feitosa, que iniciou uma pesquisa sobre a origem da cidade, primeiro movida pela curiosidade e, posteriormente, estimulada por um engajamento de manutenção da história local. Ela foi responsável por recolher relatos dos moradores mais antigos, pioneiros da região, cujas famílias já viviam à beira do rio Oiapoque desde a possível época da chegada dos grupos que vieram em busca de ouro, entre os quais se encontrava um a quem é atribuído o primeiro nome da cidade de Oiapoque, Martinica.

Segundo a professora Terezinha, informante de Romani (2010), na passagem do século XIX para o XX, os primitivos habitantes da região, antepassados dos povos Waiãpi que ocupavam a extensão territorial do rio Oiapoque, dos Galibi e Palikur concentrados no vale do rio Uaçá e seus afluentes, viram chegar pelo rio Oiapoque barcos à vela conduzindo pessoas procedentes das Antilhas, os antillesses, como ficaram conhecidos na região (ROMANI, 2010).

Os antillesses vieram acompanhando a costa da Guiana Francesa em busca do minério de 
ouro e, pela quantidade de suprimentos que trouxeram, dava a entender que receberam apoio material e financeiro do governo francês, segundo pontua Romani (2010). Eram muitos homens com suas mulheres e filhos, que também traziam animais de criação e mantimentos. Tinham como objetivo alcançar as minas de ouro existentes rio acima sob o comando de um chefe ou o líder, Émile, que por ser procedente das Antilhas, ficou conhecido na região como Émile da Martinique ou apenas Martinique. Émile tinha como missão estabelecer contato com os chefes dos filões de ouro e os donos de garimpos no rio Oiapoque acima (ROMANI, 2010).

Para alcançar seus objetivos, os antillesses realizaram incursões no rio Oiapoque, criando vários acampamentos provisórios, desde a foz até os primeiros saltos, sempre acompanhando a exploração do ouro. Nesse contexto, Romani (2010) destaca que:

[...] relações pessoais e comerciais estabelecidas nesses acampamentos montados em função dos garimpos, surge a figura do comerciante ambulante encontrando bandos de salteadores dispostos a emboscar os carregadores de ouro. Um funcionário qualquer é contratado por uma grande casa comercial para fazer a empresa do transporte das mercadorias até as casas mineradoras e, com o tempo, passa a realizar esse trabalho por conta própria, assumindo os riscos do empreendimento e sofrendo com as possíveis emboscadas às margens dos rios (ROMANI, 2010, p. 156-157).

No decorrer do tempo, esse sistema comercial articulado através de uma rede de transporte fluvial e terrestre foi se aperfeiçoando, bem como estabelecendo novas hierarquias e novos fluxos. Os primeiros mascates, à medida que acumulavam riquezas, fixavam-se em determinados acampamentos nas funções de gerente ou proprietários de casas comerciais, sendo, posteriormente, substituídos por outros. Nesse processo, pode-se encontrar a origem do povoado Martinica. É bastante provável que Émile tenha desempenhado um ou alguns desses papéis após a sua chegada ao rio Oiapoque (ROMANI 2010).

Essas histórias ou lendas até hoje contadas na cidade de Oiapoque dão conta de que a origem do povoado Martinica se encontra em um pequeno comércio montado por Émile em um desses acampamentos, que, anteriormente, teria sido uma aldeia de índios Waiäpi, no qual, à medida que o tempo passava, foi se tornando um lugar de descanso, pouso e de diversão aos que transitavam pelo rio Oiapoque em busca do ouro e outros interesses (ROMANI, 2010).

Com o declínio do ciclo do ouro no rio Oiapoque, muitas pessoas mudaram para a nova fronteira aurífera ao longo do rio Maroni, no Suriname. Destarte, ocorreu o refluxo de pessoas e a decadência econômica dos moradores dependentes da clientela dos mineradores. Nesse ínterim, Émile já se encontrava estabelecido na beira do rio e:

[...] com sua idade já avançando para os cinquenta anos, não lhe é mais possível recomeçar tudo novamente em outro lugar. A vida toma então um rumo mais calmo e sua casa passa a ser não mais uma referência de comércio, mas um lugar conhecido pelas festas e diversão oferecidas. O público que a frequenta também não é mais o mesmo (ROMANI, 2010, p. 157).

A região passou a ser habitada principalmente pelos moradores ribeirinhos, os caboclos e créoles que trabalhavam nas usinas de extração do pau-rosa, em pequenos cultivos e na pesca. A casa de Émile constituiu-se o ponto de referência para diversão, das farras animadas com músicas caribenhas e pelo tafiá, uma espécie de rum, produzido na Guiana Francesa. Ainda que considerados em caráter de lenda, Romani (2010) afirma que a lenda sobre Martinica é muito poderosa e persistente, pois "muitos mapas atuais da Guiana Francesa ainda se referem à cidade de Oiapoque com 
o nome de Martinica, outras cartas grafam ambos os nomes Oyapock, ex-Martinique" (ROMANI, 2010, p. 148). Além desses movimentos de ocupação/povoamento e formação da atual cidade de Oiapoque, Romani (2013) destaca outros próximos a atual cidade, direcionados pelo Estado brasileiro e, posteriormente, de maneira espontânea.

\section{Movimentos de ocupação e povoamento na fronteira franco-brasi- leira pelo governo brasileiro}

O primeiro movimento direcionado pelo Estado brasileiro começou em 1922 com a inauguração do Núcleo Colonial Cleveland do Norte, localizado aproximadamente a treze quilômetros da atual cidade de Oiapoque, fruto dos seguintes interesses: i) resolver o problema dos considerados indesejáveis proveniente da grande seca cearense de 1915, cujos migrantes se encontravam acampados em Belém do Pará; ii) valorização das terras na região dos latifundiários paraenses; e iii) a necessidade de povoamento na fronteira para inibir a presença de estrangeiros. Assim aconteceu a primeira tentativa do governo brasileiro em assegurar o povoamento do vale do rio Oiapoque. Essa ação governamental atendia por um lado à urgência da integração da área ao território nacional e, por outro, promovia a civilização da reduzida população cabocla que lhe habitava (ROMANI, 2013, p. 180).

Para o autor existiram dois fatores fundamentais que levaram o Estado brasileiro a direcionar seus recursos humanos e materiais na fronteira da área anexada. O primeiro, motivado pela:

[...] presença constante de estrangeiros atravessando as fronteiras, circulando pelo território brasileiro e explorando-o comercialmente. Os franceses da Guiana durante muitos anos, desde os tempos da disputa no Contestado e nos vinte anos que se seguiram à definição da soberania brasileira sobre o território, continuaram sendo a maioria da população "civilizada" do lugar (ROMANI, 2013, p. 179).

Se, por um lado, para alguns franceses, a sentença do laudo de Berna não encerrava de forma definitiva a questão do Contestado do ponto de vista jurídico e político, por outro, o descuido do governo brasileiro pela área anexada contribuía para que os franceses acreditassem que o novo limite da fronteira só existisse no papel. Tanto que o relatório do comissário francês Brousseau, publicado em setembro de 1919, falava do território além do rio Oiapoque como pertencente à Guiana Francesa, referindo-se a ele como uma área com grandes possibilidades de riquezas vegetais e minerais. De acordo com Alicino (1971), o relatório dizia ainda que "[...] do ouro que os franceses tinham extraído daquela região antes do laudo suíço, com algarismo estonteantes, de 25 a 30 milhões de francos" (ALICINO, 1971, p. 73).

Quanto ao segundo fator, talvez o mais importante para os interessados, foram os aspectos econômicos, "[...] pois tratava-se de uma região rica em recursos naturais na floresta, entre eles as essências, as madeiras de lei e o látex, e os recursos minerais, principalmente o ouro que se imaginava ainda poder ser encontrado nos afluentes do rio Oiapoque" (ROMANI, 2013, p. 180).

No entanto, os responsáveis pela implantação do Núcleo Colonial Cleveland do Norte, que tinham como propósito povoar por meio da agricultura, negligenciaram os estudos do solo, priorizando a topografia do lugar, os recursos minerais e extrativos existentes. Na prática, o solo apresentou baixa fertilidade, e o pouco que era produzido não tinha compradores. Além disso, grande parte dos colonos abandonaram as atividades agrícolas e passaram a morar na vizinha Martinica, trabalhar na extração do pau-rosa e na garimpagem do ouro (ROMANI, 2013). 
O insucesso do povoamento pela agricultura, a necessidade de salvar o investimento feito no Núcleo Colonial Cleveland do Norte e a revolução dos tenentes em 1924, levou o governo brasileiro ao segundo movimento colonizador. Na noite do dia 25 de dezembro de 1924, chegou ao Núcleo Colonial Cleveland do Norte um navio a vapor conduzindo o primeiro lote de prisioneiros com, aproximadamente, 1.200 pessoas (ALICINO, 1971; ROMANI, 2013).

A nova ordem imposta no Núcleo Colonial Cleveland do Norte, com a chegada dos exilados políticos, era mantida, a princípio, por uma equipe militar paraense composta de 50 homens que não conseguia conter as sucessivas fugas ocorridas. No primeiro semestre de 1925 foi enviado um destacamento de 150 homens; reforço esse que não foi suficiente para inibir as fugas dos presos, que iam para Martinica em busca de diversão (ALICINO, 1971; ROMANI, 2013).

Por meio dessas formas distintas de ocupação, o Estado brasileiro tentou povoar e exercer sua soberania na fronteira norte do Brasil usando uma população de indivíduos considerados socialmente indesejáveis por diferentes motivos. Romani (2013, p. 182) assevera que "[...] além da militarização da colônia agrícola, fenômeno corriqueiro na história brasileira, o Núcleo Colonial Cleveland do Norte assistiu, de modo inusitado, a transformação de suas terras em local de desterro de presos políticos".

Baseado nessas informações, pode-se dizer que o rigor disciplinar implementado no Núcleo Colonial Cleveland do Norte era o responsável por vetar qualquer modalidade de festa, farras ou entretenimento recreativo por parte dos presos, o que contribuiu para o crescimento de Martinica. Os presos que estavam condicionados ao duro regime do Núcleo Colonial viam-se limitados para dar vazão aos seus divertimentos e prazeres mais terrenos, fugindo para lá a procura de diversão. Essa demanda se mostrou tão alta e recorrente que apenas a casa de Émile não se mostrou suficiente como ponto de recepção festiva. É então que, por iniciativa de um deportado de Cleveland do Norte, organizou-se o Clube Recreio da Mocidade (ALICINO, 1971).

Com iniciativas como essa, o lugarejo foi se desenvolvendo e atraindo os primeiros comerciantes (ALICINO, 1971). Assim, entre 1925 e 1927, dois fatores contribuíram para o aumento das atividades econômicas e sociais de Martinica. O primeiro, em 1925 foi a transferência da usina de extração de essência de pau-rosa, da localidade denominada Ponta dos Índios, para a localidade que hoje é a atual cidade de Oiapoque; o segundo fator se deu em virtude da anistia política dos exilados, que aconteceu por volta de 1927 e teve como consequência o retorno de prisioneiros e militares. Dessa maneira, a vida na colônia agrícola declinou e os que não regressaram para suas localidades natais, transferiram-se para o vizinho povoado Martinica (ALICINO, 1971; ROMANI, 2013).

Os colonos que não conseguiram mais viver da agricultura em Martinica, passaram a sobreviver da pesca e dos salários de trabalhos realizados nas usinas de extração de essência de paurosa, baunilha e de aguardente instaladas ao longo do rio Oiapoque, tanto no lado francês quanto do lado brasileiro. Essas atividades industriais extrativistas, somadas à agricultura de subsistência, à pesca artesanal e à sobra das verbas do governo, passaram a sustentar a vida econômica e social do que viria se tornar a cidade de Oiapoque (ROMANI, 2011).

Em Martinica, as pessoas faziam compras de produtos básicos e dos excedentes da agricultura. Porém, para comprar produtos diferentes do trivial - alimentos, bijuterias, perfumarias e roupas mais finos - cruzavam o rio Oiapoque em direção a Saint-Georges, onde encontravam objetos vindos diretamente da França. As instalações da atividade industrial extrativista e a decadência do Núcleo Colonial Cleveland do Norte trouxeram para Martinica uma farta mão de obra barata, empreendedores e pequenos comerciantes. Começava aí a se desenhar os primeiros contornos do que 
se tornaria uma divisão social, em que, de um lado, estava uma elite migrante e, do outro, um grupo de assalariados (ROMANI, 2011).

A exploração "desordenada" das essências do pau-rosa levou à escassez da matéria-prima e à transferência das usinas para outras regiões, suscitando um processo de colapso da frágil economia de Martinica. Situação que veio mudar de forma expressiva no início do ano de 1932 com a descoberta dos veios de ouro nas cabeceiras dos rios Cassiporé e Oiapoque, atraindo muitos garimpeiros, guianenses - os crioulos - e brasileiros moradores da costa amapaense, da foz do Amazonas, Maranhão e de Itaituba, no Pará (ALICINO, 1971).

\section{A continuidade das atividades garimpeiras motivando a presença do estado brasileiro na fronteira franco-brasileira}

Apesar de Romani (2011) e Alicino (1971) afirmarem que esse ciclo do ouro iniciou em 1932 e terminou em 1935, com o esgotamento da exploração aurífera, Moraes (1964) pontua que o relatório apresentado em 1957 à Comissão Demarcadora de Limites do Ministério das Relações Exteriores, sob o título geral Missão no Rio Oiapoque, informa que:

\footnotetext{
[...] tanto o rio Oiapoque, quanto alguns de seus numerosos afluentes, são auríferos. Entre os tributários da margem esquerda, são famosos os rios Sikini e Camopi, ao passo que na vertente brasileira se apontam os rios Taparabô, Açaizal, Pantanari, Anotaie, Marupi. Iauê, Muturá, Ingarari e Mutacuera. Entretanto, a atividade dos faiscadores limita-se, no momento, somente a depósitos afastados do rio Oiapoque, e apenas na Guiana Francesa (Camopi, Sikini). [...] O fato é que o ciclo do ouro não está encerrado e até em Boa Esperança [Vila Brasil] do Camopi a moeda corrente é o grama-ouro, tanto que nos pediram um "grama e meio", por uma melancia (MORAES, 1964, p. 18-19).
}

À medida que ia se intensificando a exploração do precioso metal no rio Oiapoque e seus afluentes, ocorria uma verdadeira disputa das águas dos igarapés entre os índios dominadores da região e os garimpeiros. Avolumava-se, então, o comércio em Martinica e se dá o surgimento das casas comerciais Aveirense e Vencedora - de Antônio Gonçalves Faria e de Zacarias Neves, respectivamente - nas quais eram realizadas a compra de ouro para o Banco do Brasil (ALICINO, 1971, p. 119).

Assim, sustentando-se ora no extrativismo vegetal, ora no mineral, a economia da região foi mantida pelo trabalho braçal dos caboclos nativos, dos migrantes nacionais e dos imigrantes créoles. Este caldo étnico e cultural singular permitiu o surgimento, em Martinica, de um polo de diversão bastante apreciado pelos moradores das redondezas. Festas periodicamente realizadas em residências como a de Émile tornaram-se atrações conhecidas. Somaram-se a elas as celebrações religiosas oficiais, trazidas pela Igreja Católica e pelo Estado brasileiro, as quais pretendiam civilizar e cristianizar a predominante religiosidade da população negra e crioula, assinalada por práticas religiosas com origens nas religiões de raízes africanas (ROMANI, 2011).

O crescimento espontâneo de Martinica, principalmente em função das atividades extrativistas vegetais (essências) e minerais (ouro), chegou a um ponto que não pôde mais ser ignorado pelo Estado brasileiro. Em 1924 foram organizados o Cartório de Registro Civil, Serviço dos Correios e a Coletoria Estadual (ROMANI, 2010).

No mês de fevereiro de 1927, o General Cândido Rondon, em uma inspeção pela região, visitou o povoado de Martinica e ao "[...] achar-lhe sabor francês no nome, lhe mudou para 'Vila 
do Espírito Santo"' (ALICINO, 1971, p.118). Além de mudar o nome, o general se empenhou na construção da estrada de rodagem para ligar Cleveland ao povoado do Espírito Santo, e em apagar os vestígios estrangeiros da memória local, fazendo com que os documentos oficiais da fundação da cidade apresentassem o mínimo possível de referências a essa antiga origem, relegando a perpetuação da origem da cidade apenas à memória da população (ROMANI, 2010, 2011).

O propósito do general foi conseguido, visto que os documentos oficiais da fundação da cidade trazem poucas referências a essa origem. Assim, Romani (2010) assinala que, para o governo brasileiro, a história de Oiapoque tem início com a chegada das instituições nacionais trazidas pela colônia agrícola e pelos destacamentos militares na década de 1920. Esse pensamento, por seu turno, foi compartilhado e concretizado pelos setores da sociedade que se afirmaram como a nova elite econômica e política local; elite essa empenhada em minimizar a real origem de Martinica e valorizar a colonização induzida pelo Estado como o marco oficial da fundação da localidade (ROMANI, 2010, 2011).

Contudo, ainda hoje, muitos habitantes da cidade de Oiapoque, principalmente os mais antigos, seus descendentes e os que se interessam pela história da Martinica, além de não esquecerem o que para alguns pode ser considerado lenda, contribuem com informações para preservar a memória da origem da cidade, em especial os descendentes dos moradores ribeirinhos que lá chegaram, antes do início do processo de colonização oficial (ROMANI, 2010, 2011).

Na década de 1940, o Amapá foi desmembrado do estado do Pará e transformado em Território Federal do Amapá. O Capitão Janary Gentil Nunes, na condição de interventor da nova unidade federativa, desmembrou o distrito de Oiapoque do município do Amapá, e elevou-o à categoria de município em 13 de maio de 1945. A cidade de Oiapoque foi transformada em sede administrativa do recém-criado, ainda que não possuísse os equipamentos necessários para as suas funções e padecesse de dificuldades de transporte e abastecimento (ALICINO, 1971).

De 1945 até o final da década de 1960, os órgãos governamentais do Território Federal do Amapá procuraram enfrentar as dificuldades no município e começaram a construção de prédios em alvenaria para abrigar os serviços de utilidade pública: escola, posto médico, Legião Brasileira de Assistência, Comarca de Oiapoque, usina de luz, assim como também as habitações para os funcionários da prefeitura (ALICINO, 1971).

Nesse sentido, Alicino (1971) também ressalta que outras ações foram realizadas por parte do Estado, pois:

o centro urbano foi dotado de um plano urbanístico que logo entrou em função, promovendo arruamento bem esquadrejados e terraplanagem dos pontos mais escabrosos. O problema do aproveitamento hídrico foi resolvido com a construção da caixadágua e de rede de distribuição. Foi instalada a rêde [sic] elétrica de distribuição. Operou-se também o saneamento da beira, com a construção de um muro ciclópico e cais (ALICINO, 1971, p. 124).

As esperanças dos 4.425 oiapoquenses de se conectarem via terrestre com o restante do Território Federal do Amapá, bem como a consequente possibilidade de desenvolvimento, cresceram em 1970 com a inauguração da Rodovia Barão do Rio Branco, a atual BR-156, que tinha como um dos objetivos garantir a presença do Estado brasileiro na fronteira franco-brasileira. Apesar das precariedades da rodovia recém-construída, a cidade de Oiapoque estava finalmente ligada, por via terrestre, à capital do Estado do Amapá, a cidade de Macapá (ALICINO, 1971).

Decorrida uma década da inauguração da BR-156, o município de Oiapoque apresentava 
uma população de $5.028^{8}$ habitantes, dos quais 2.513 habitavam na área rural e 2.515 na urbana. Esta última, composta por algumas ruas e avenidas do atual Bairro Central, era onde se concentravam os poucos domicílios e comércios que abasteciam o município com suprimentos básicos que se destinavam para Clevelândia do Norte ou regressavam da Guiana Francesa por militares e familiares (SOARES, 1995).

Dois fatores vieram a mudar, de forma expressiva, a vida econômica e social da cidade de Oiapoque. O primeiro, no final da década de 1980 e início da década de 1990, foi a descoberta de novas jazidas de ouro no rio Oiapoque, enquanto o segundo caracteriza-se pela necessidade de trabalhadores para as obras realizadas na BR-156. A partir de então, Soares (1995) destaca que:

[...] o município de Oiapoque passou por uma grande experiência como ponto de apoio passagem para garimpos. Tratava-se da exploração de garimpos no médio e alto rio Oiapoque. Os garimpos situados no território brasileiro chegaram a ocupar em torno de 5.000 pessoas em atividades relacionadas com a extração aurífera naquela área. [...] A dificuldade de acesso para aqueles garimpos só se iniciava a partir da cidade de Oiapoque, obrigando a travessia de inúmeras e perigosas cachoeiras, num percurso em que se levam dias de viagem pelo rio Oiapoque, a montante, para se chegar ao destino (SOARES, 1995, p. 51).

A nova exploração de ouro por meio de balsas ou flutuantes, iniciada nos sedimentos do rio e seus afluentes, teve como apoio logístico a cidade de Oiapoque e foi facilitada pelas melhorias realizadas pelo Estado na BR-156, que alterou a condição de Oiapoque como ponto de passagem para os que se destinavam ir à Guiana Francesa (SOARES, 1995; MATHIS 2012).

A intensificação das "passagens" e o incremento do tempo de espera dos envolvidos na garimpagem de ouro não eram bem vistos pelos radicados na cidade, haja vista a alteração indesejada no modo de vida local. Os que chegavam com a finalidade de trabalhar no garimpo passavam diversas horas do dia sentados na mureta do cais ou sob uma frondosa mangueira, conhecida como "árvore do blefe", próxima do mercado municipal, com a esperança de serem recrutados pelos donos de garimpos. A eles eram atribuídas tanto a desordem na orla fluvial quanto as ocorrências incomuns na cidade, como assassinatos, brigas e a elevação da prostituição, que se agravava com a falta de energia elétrica que funcionava dia sim, dia não (SOARES, 1995).

O grande número de garimpeiros em trânsito por tempo prolongado e a pouca oferta no comércio de serviços locais para atender as novas demandas contribuíram para o aumento desordenado de abrigos improvisados e a informalidade de ambulantes. $\mathrm{Na}$ tentativa de solucionar o caos provocado pelos ambulantes na orla fluvial "[...] a prefeitura construiu o mercado municipal para organizar uma feira de venda de comidas e roupas, com barracas cobertas de lona que tomava conta da rua principal, que margeia o rio Oiapoque (Rua Caetano Silva)" (SOARES, 2007, p. 32).

Nesse contexto, os radicados na cidade de Oiapoque viam um grande contraste entre o novo movimento - muita gente, longas permanências, pessoas com e sem posses, novos comércios, novas mercadorias, novos prestadores de serviços e a pacata rotina que imperava há décadas na cidade ${ }^{10}$.

8 "Em 1980, 12,7\% dos moradores recenseados estavam instalados há menos de 10 anos no município,
sendo que $80 \%$ deles de quatro procedências: 255 (39\%) de outros municípios do mesmo Estado, 208
(32\%) do Estado do Pará, 41 (6,3\%) do Estado do Maranhão e 20 (3,1\%) de origem estrangeira" (SOARES,
2007, p. 32).
9 De acordo com Soares (2007), o local era “[...] ponto de encontro de quem está sem emprego, de quem
não foi bem-sucedido nas expectativas de logo entrar para o garimpo [...]" (SOARES, 2007, p. 32).
10 Quando servia mais como ponto de passagem para: pequenos comerciantes que iam e vinham de Caiena 
Assim sendo, a espera na cidade de Oiapoque se intensificou a partir de 1991. Até então o atravessamento da fronteira franco-brasileira para quem quisesse garimpar era praticamente livre. No entanto, houve alteração nessa dinâmica, uma vez que a entrada para trabalhar no garimpo passou a ser controlada pelas autoridades da Guiana Francesa mediante a exigência de passaporte, de comprovantes de residência e de fotografias de identificação. Tais formalidades, inicialmente, tomaram de surpresa aqueles que retornavam para o garimpo ou que chegavam pela primeira vez (SOARES, 2007).

O controle agregava ônus financeiros inacessíveis à maioria dos fluxos, contribuindo para o aumento do tempo de espera e o desconforto dos radicados na cidade de Oiapoque. Dessa maneira, os garimpeiros começaram a receber estigmas sociais ${ }^{11}$. Antes mesmo de transpor a fronteira internacional, estabeleciam-se preconceitos comparáveis aos que os brasileiros sentiam no interior da Guiana Francesa, situação agravada por ali tratar-se da figura do estrangeiro, com todas as implicações advindas dessa condição (SOARES, 1995).

As exigências, contudo, não inibiram a busca da garimpagem clandestina de ouro em solo guianense, pois, conforme Soares (2007), a procura pelos garimpos brasileiros se intensificou principalmente a partir da década de 1990, com o início da Operação "Selva Livre", capitaneada pelo então Presidente Fernando de Collor Melo (1990-1992). Assim, enquanto o objetivo interno era a desarticulação da atividade garimpeira realizada no interior dos territórios indígenas do estado de Roraima, o objetivo externo consistia em melhorar a imagem do Brasil na conferência da Organização das Nações Unidas sobre Meio-Ambiente, que seria realizada no Rio de Janeiro, em junho de 1992.

Com as restrições impostas pelo governo francês e o combate à garimpagem de ouro no Brasil, aumentava o contingente de pessoas chegando à cidade de Oiapoque, assim como o seu tempo de espera. Os que aguardavam uma oportunidade de entrar para o garimpo, com poucos ou sem recursos financeiros, dividiam despesas com aluguel ou alojavam-se em prédios públicos desocupados, construções particulares inacabadas cedidas por conhecidos na cidade, e barracões ${ }^{12}$ construídos por comerciantes de Oiapoque (SOARES, 1995).

Nesse conjunto de articulações envolvendo os garimpeiros, havia certa solidariedade entre empresários do comércio em Oiapoque e dos garimpos franceses na exploração e captação de renda-trabalho antes de sua concretização, tendo como combustível os trabalhadores que se vinculavam aos patrões donos dos maiores estabelecimentos de extração de ouro dentro da Guiana Francesa, antes, durante e depois do período de trabalho. Essa era uma das faces da fronteira relativizada e das relações comerciais transnacionalizadas (SOARES, 2007).

Na argumentação de Romani (2010), Alicino (1971), Superti e Silva (2015), Almeida e Rauber (2017), Castro e Hazeu (2012), atribui-se à garimpagem de ouro uma centralidade concernente

com sacolas de perfumes e bebidas; aqueles que iam e vinham para Clevelândia - militares e seus familiares, principalmente para fazer compras no comércio da cidade de Oiapoque; pessoas provenientes da Guiana Francesa, precisamente de Saint-Georges - que procuravam a cidade esporadicamente para fazer pequenas compras ou mesmo como turistas de passagem "para o Brasil" por via terrestre, através da Rodovia BR-156 (SOARES, 2007).

11 Como forma de atenuar os estigmas, alguns garimpeiros procuravam agir conforme os costumes locais na esperança de serem absorvidos como morador da cidade (SOARES, 2007).

12 Eram chamados de barracões aqueles "[...] prédios rústicos edificados geralmente em ruas situadas fora do pequeno centro comercial e residencial. Geralmente não têm paredes, mas apenas esteios fincados (onde são armadas as redes de dormir) com cobertura de telhas de amianto. Durante o dia as redes são desarmadas e amarradas próximo a um de seus punhos. Num cercado, como prateleiras, são colocadas as 'borocas', onde guardam os pertences pessoais” (SOARES, 2007, p. 39). 
ao dinamismo econômico observado na cidade de Oiapoque. Essas inferências são reiteradas no presente por meio de entrevistas com os informantes, em especial antigos moradores, que chamam atenção para a falta de conhecimento quanto ao papel que a garimpagem de ouro desempenhou na fronteira franco-brasileira e na gênese da cidade, bem como suas contribuições em termos de geração de trabalho e renda.

Em decorrência dessa percepção, as operações franco-brasileiras de combate a essa atividade - devido aos danos ambientais que provoca - são bastante criticadas. Todavia, ressalta-se que, neste momento, apontar o aspecto de legalidade da atividade garimpeira e seu impacto ambiental não é o cerne da discussão proposta neste artigo, mas, sim, discutir o papel social daqueles indivíduos envolvidos direta ou indiretamente na garimpagem de ouro como agentes produtores do espaço urbano na cidade de Oiapoque.

Os fluxos e práticas espaciais ${ }^{13}$ descritos dos agentes de atividades vinculadas à garimpagem de ouro nas motivações dos litígios e definições de limites entre Brasil e França se expressam, ainda hoje, nas negociações de compra e venda de mercadorias, combustíveis, equipamentos “[...] de euro e ouro, nos pequenos portos da orla da cidade, onde atracam as catraias com passageiros vindos de Saint-George" e "sua oscilação em função de variáveis também locais, interliga essa cidade do extremo Norte do País a redes mais extensas” (CASTRO; HAZEU, 2012, p. 27).

\section{Considerações Finais}

Mediante o exposto, nota-se que a cidade de Oiapoque constitui um eixo de relações entre indivíduos nacionais e internacionais. Isso porque, na fronteira franco-brasileira, além de brasileiros, indígenas e quilombolas, também habitam cubanos, haitianos, colombianos, venezuelanos e outros sul-americanos que são motivados pelo mercado de euro e ouro, mercado esse fortemente dinamizado por interesses externos.

Como desdobramento dessas relações e práticas comerciais, a logística para atender às demandas das atividades relacionadas à exploração e à renda da garimpagem do ouro encontra-se centralizada no núcleo urbano da cidade de Oiapoque. Essas redes de atividades, chamadas de "economia do garimpo", tornaram-se verdadeiros vetores de adensamento urbano a partir, principalmente, do núcleo citadino de Oiapoque, mobilizando pessoas e estimulando a circulação monetária (ALMEIDA; RAUBER, 2017).

Ainda no que diz respeito a esses vetores, tem-se que são apontados pelos que habitam na cidade de Oiapoque como fatores predominantes e positivos, pelo impacto econômico da atividade garimpeira, cuja movimentação financeira, estimulada pelo negócio do ouro, sempre garantiu a sobrevivência de milhares de pessoas. Outro aspecto considerado positivo, sendo este de um campo mais simbólico da percepção local, era o que considerava a trajetória da localidade atrelada à mineração, onde residia o protagonismo da atuação dos garimpeiros. Esses trabalhadores, frequentemente apontados como os fundadores da cidade, também podem ser considerados, nesse sentido, como verdadeiros agentes produtores do espaço urbano oiapoquense.

\footnotetext{
13 Este termo, na afirmação de Schmid (2012), caracteriza o sistema que resulta da articulação e conexão de elementos ou atividades. Ademais, poder-se-ia pensar como as redes de interação e comunicação se erguem na vida cotidiana (por exemplo: a conexão diária que se faz entre casa e o local de trabalho) ou no processo de produção (por exemplo: as relações de produção e troca).
} 


\section{Referências}

ACEVEDO MARIN, Rosa Elisabeth. Civilização do rio, civilização da estrada: transportes na ocupação da Amazônia no Século XIX e XX. Papers do NAEA, Belém, n. 170, p. 1-25, maio 2004.

ALICINO, Rogério. Clevelândia do Norte. Rio de Janeiro: Biblioteca do Exército-Editora, 1971. (Coleção Taunay).

ALMEIDA, Carina Santos; RAUBER, Alexandre Luiz. Oiapoque, aqui começa o Brasil: a fronteira em construção e os desafios do desenvolvimento regional. Redes, Santa Cruz do Sul, v. 22, n. 1, p. 474-493, jan./abr. 2017.

BECKER, Bertha Koiffmann. Amazônia. 4. ed. São Paulo: Ática, 1997.

BECKER, Bertha Koiffmann. Amazônia: geopolítica na virada do III milênio. Rio de Janeiro: Garamond, 2004.

CARDOSO DE OLIVEIRA, Roberto. Identidade, Etnicidade e Nacionalidade no Mercosul. Política Comparada, Brasília, v. 33, n. 2, p. 45-62, maio/ago. 1997.

CASTRO, Edna Maria Ramos de; HAZEU, Marcel. Cidades, fronteiras transnacionais e migração na Pan-Amazônia. Somanlu, Manaus, v. 12, p. 17-43, 2012.

COELHO, Maria Célia Nunes; WANDERLEY, Luiz Jardim; COSTA, Reinaldo. Garimpeiros de ouro e cooperativismo no século XXI. Exemplos nos rios Tapajós, Juma e Madeira no Sudoeste da Amazônia brasileira. Confins, Paris, n. 33, 2017.

COELHO, Mauro César; QUEIROZ, Jonas Marçal. Amazônia: modernização e conflito (séculos XVIII e XIX). Belém: UFPA/NAEA; Macapá: UNIFAP, 2001.

CORBIN, Hisakhana Pahoona. Migração de brasileiros para a Guiana como estratégia de sobrevivência. Belém: NAEA, 2012.

COSTA, Jodival Maurício da; CUNHA, Lúcio. Serviços ecossistêmicos e políticas de alterações climáticas na Amazônia. In: COSTA, Jodival Maurício da (org.). Amazônia: olhares sobre o território e a região. Rio de Janeiro: Autografia; Macapá: UNIFAP, 2017. p. 21-42.

GÓES, David Souza. Garimpagem de ouro na fronteira Amapá Guiana Francesa: subsídios para políticas públicas. 2014. 125 f. Dissertação (Mestrado em Direito Ambiental e Políticas Públicas) - Programa de Pós-Graduação em Direito Ambiental e Políticas Públicas, Universidade Federal do Amapá, Macapá, 2014.

GRANGER, Stéfhane. Guiana Francesa entre França e Brasil: da colonização à continentalização. In: PORTO, Jadson Luís Rebelo; DOFF SOTTA, Eleneide (org.). Reformatações fronteiriças no Platô das Guianas: (re) territorialidade de cooperações em construção. Rio de Janeiro: Publit, 2011. p. 71-91.

LEFÈBVRE, Henri. La production de l'espace. 4. ed. Paris: Anthropos, 2000.

LINS, Fernando Freitas (coord.). Aspectos diversos da garimpagem de ouro. Rio de Janeiro: CETEM/CNPq, 1992. (Série Tecnologia Mineral, 54).

MARTINS, Carmentilla das Chagas. Para além, através, da fronteira e do acordo: interações sociais no Oiapoque. 2013. 179 f. Tese (Doutorado em Ciências Sociais) - Centro de Pesquisa e PósGraduação em Sociologia e Antropologia, Universidade Federal do Pará, Belém, 2014.

MATHIS, Armin. Extração versus conservação - garimpagem de ouro e política de conservação no estado do Amapá. Papers do NAEA, Belém, n. 289, p. 1-23, jan. 2012.

MORAES, João de Mello. O Rio Oiapoque. Revista Brasileira de Geografia, Rio de Janeiro, v. 26, n. 1, p. 3-61, 1964. Disponivel em: https://biblioteca.ibge.gov.br/visualizacao/periodicos/115/ rbg_1964_v26_n1.pdf. Acesso em: 11 jan. 2020. 
REIS, Arthur Cezar Ferreira. Território do Amapá: perfil histórico. Rio de Janeiro: Departamento de Imprensa Nacional, 1949.

RODRIGUES, Francilene dos Santos. Garimpagem e mineração no norte do Brasil. Manaus: EDUA, 2008.

ROMANI, Carlo. A história entre o oficial e o lendário: interações culturais no Oiapoque. Antíteses, Londrina, vol. 3, n. 5, p. 145-169, jan./jun. 2010.

ROMANI, Carlo. Clevelândia, Oiapoque: cartografias e heterotopias na década de 1920. Boletim do Museu Paraense Emílio Goeldi. Ciências Humanas, Belém, v. 6, n. 3, p. 501-524, 2011.

ROMANI, Carlo. Aqui começa o Brasil!: histórias das gentes e dos poderes na fronteira do Oiapoque. Macapá: Editora Multifoco, 2013.

SANTOS, Milton. A natureza do espaço: técnica e tempo, razão e emoção. 4. ed. 2. reimpr. São Paulo: EDUSP, 2006.

SCHMID, Christian. A teoria da produção do espaço de Henri Lefebvre: em direção a uma dialética tridimensional. GEOUSP: Espaço e Tempo (Online), São Paulo, n. 32, p. 89-109, 2012.

SILVA, Gutemberg de Vilhena. Oiapoque: potencialidades e caminhos neste século XXI. Macapá: UNIFAP, 2014.

SOARES, Ana Paulina. Travessia: análise de uma situação de passagem entre Oiapoque Guiana Francesa. 1995. 112 f. Dissertação (Mestrado em Geografia) - Faculdade de Letras, Filosofia e Ciências Humanas, Universidade de São Paulo, São Paulo, 1995.

SOARES, Ana Paulina Aguiar. Travessia: uma situação de passagem entre o Brasil e a Guiana Francesa. Revista de Estudos Amazônicos, Manaus, p. 23, 2007.

SPRANDEL, Márcia Anita. Breve genealogia sobre os estudos de fronteiras e limites no Brasil. In: OLIVEIRA, Roberto Cardoso de; BAINES, Stephen (org.). Nacionalidade e etnicidade em fronteiras. Brasília: Editora Universidade de Brasília, 2005. p. 153-203. (Coleção Américas).

SUPERTI, Eliane; SILVA, Gutemberg Vilhena. Integração internacional e políticas públicas de defesa e segurança na fronteira setentrional amazônica: Reflexões sobre a condição fronteiriça amapaense. Intellector, Pelotas, v.11, n. 22, p. 129-147, 2015.

THEIJE, Marjo; LUNING, Silver. Small Scale mining and cross-border movements of gold from French Guiana. In: COLLOMB, Gilbert; MAM LAM FOUCK, Stephen (ed.). Mobilités, ethnicités, diversité culturelle: la Guyane entre Suriname et Brésil. Elements de compréhension de la situation guynaise. Matoury: Ibis Rouge, 2016. p. 141-161.

TRINDADE JÚNIOR, Saint-Clair Cordeiro da. Pensando a noção de fronteira: um olhar a partir da ciência geográfica. In: NASCIMENTO, Durbens Martins do (org.). Amazônia e defesa: dos fortes às novas conflitualidades. Belém: NAEA-UFPA, 2010. p. 101-123.

Artigo recebido em: 24/06/2020

Artigo aceito em: 29/07/2020 